\title{
Whole Brain Creativity Model: Implications for Nursing Education and Practice
}

\author{
E Potgieter \\ D Litt et Phil \\ Department of Advanced Nursing \\ Sciences \\ UNISA
}

\section{abstract}

Recent nursing literature has repeatedly proclaimed the need for creativity in nursing. Effective nursing practice in the new millennium will require innovative and creative nurses who can adapt to change and have the courage to take risks in order to provide holistic, individualised, context-specific care.

An analytical study of the literature revealed interesting information on the concept creativity and teaching for creativity. The aim of this article is to describe the Whole Brain Creativity Model and its implications for nursing education and practice.

\section{opsomming}

Die behoefte aan kreatiwiteit in verpleging word herhaaldelik aangespreek in hedendaagse verpleegliteratuur. Effektiewe verpleegpraktyk in die nuwe millennium, sal innoverende en kreatiewe verpleegkundiges verg wat kan aanpas by verandering en die moed het om te waag ten einde holistiese, geïndividualiseerde, konteksspesifieke sorg te kan lewer. 'n Analitiese literatuurstudie het interessante inligting oor die konsep kreatiwiteit en die ontwikkeling van kreatiwiteit deur onderrig, openbaar. Die doel van hierdie artikel is om die Heelbrein Kreatiwiteitsmodel te beskryf en die implikasies daarvan vir verpleegonderwys en praktyk, aan te dui.

\section{introduction}

The fostering of creativity in nursing education has been the subject of much debate in recent years. Nurse educators have expressed increasing concern with regard to the expression and development of creativity in nursing. Seen against an accelerating changing society, marked by changing human values, expanding knowledge and improved technology, nursing is becoming an increasingly diverse profession. The nurse in the 21 st century will have to be a creative and innovative practitioner to be able to cope effectively with new and unique elements in a complex health care setting.

Nursing as an evolving and maturing professional discipline is experiencing a major paradigm shift as a result of the rapid changes in health care delivery throughout the world: The nursing profession today seeks a nurse who can function in a highly scientific and technological milieu. The nurse practitioner of tomorrow will have to accept the ambiguities of a modern and dynamic medical and health care setting - a complex world in which there are no certainties or any clear and easy solutions.

Bevis and Watson in Towards a caring curriculum: a new pedagogy for nursing summarises the new paradigm for nurs- ing as follows:

"We must find a balance, a truce, a truly liberated climate for teaching of inquiry, so that we fuse the scientific with the metaphysical, and infuse a new respect for those things uniquely human: morality, judgement, intuition, reflection, imagination, creativity, values, meaning and spiritual sensitivity." (Bevis \& Watson 1989:64)

\section{research methodology}

An exploratory descriptive design comprising an analytical study of the literature on creativity, was utilised. The most important methodological considerations in descriptive studies are to gather accurate data about a phenomenon. Assumptions (not hypotheses), are therefore stated in this type of research design. This study is based on the assumption that there is a pressing need for creativity in nursing and the aim is to analyse and describe the Whole Brain Creativity Model and indicate the implications for nursing education and practice.

\section{the concept creativity}

The word creativity has been both misused and overused and the concept it stands for is vague, general and confus- 
ing. As it refers to a very complex aspect of human behaviour, it has many different meanings to as many different people. It is therefore not possible to offer a universally acceptable definition. However, when we use the concept creativity we open ourselves to misunderstanding unless we define and explain how we view creativity. The literature on creativity generally discloses two opposing approaches. The traditional view regards creativity as a special talent belonging to a few superior individuals, creative geniuses as they are often referred to. According to this view the creative ability is unchangeable and exists only in individuals who have inherited it genetically. It is believed that this kind of creativeness cannot be fostered, nor can it be fully comprehended because of the eccentricity of the creative genius. The only way to partially understand this kind of creativeness is through the creative product as delivered by people such as Darwin, Einstein, Da Vinci and Poincaré.

A more recent approach towards creativity results from contemporary research. Creativity is viewed as an au thentic human ability which manifests it- self in different human activities. It is not the prerogative of a few selected human beings, but exists in all human beings and can be encouraged by education and a suitable environment (Prinsloo 1973:44-45; Oschse 1990:3).

The focus of the article is on the more recent approach towards creativity and I shall suffice by the following two definitions of creativity:

Henle:The creative solution, the creative idea, is one which the individual achieves by freeing himself from his own conceptual system, and by which he sees in a deeper or more comprehensive or clearer way the structure of the situation he is trying to understand.

Abraham Maslow: Selfactualising creativeness - these people can see the fresh, the raw, the concrete, the idiographic, as well as the generic, the abstract, the rubricised, the categorised and the classified. Consequently they live far more in the real world of nature than in the verbalised world of concepts, abstractions, expectations, beliefs and stereotypes that most people confuse with the real world. (Prinsloo 1973:47, 49)
Henle expresses the necessity for the individual to free himself from his own conceptual systems, in other words his usual way of thinking, in order to enable himself to see deeper and more comprehensively. Maslow focuses on this very same phenomenon, the individual's ability to perceive the concrete and the ideographic, as well as the abstract and the generic, implies perceiving holistically.

\section{whole brain creativity}

The split brain studies which started during the 1960's, demonstrated significant differences between the functions of the left and the right hemispheres of the brain. These studies together with the vast amount of research studies initiated since, have led to the psychophysiological approach to the analysis of mental functioning which has gained great impetus. The new knowledge generated through this approach which includes the concept of cerebral dominance (implying that one hemisphere tends to play a more important role than the other in each individual), has resulted in a new understanding of the nature and process of learning with far-reaching impli-

\begin{tabular}{|c|c|}
\hline LEFT & RIGHT HEMISPHERE SPECIALISATION \\
\hline $\begin{array}{l}\text {-Verbal: encoding and decoding speech, reading, writing, } \\
\text { spelling, mathematics, musical notation } \\
\text {-Analytic: things are figured out part-by-part } \\
\text { - Linear: think in terms of linked ideas, process information } \\
\text { sequentially, often leads to a convergent conclusion } \\
\text { - Convergent thinking } \\
\text { - Logical: draw conclusions based on logic, one thing follow } \\
\text { another in logical order } \\
\text { - Conscious reasoning } \\
\text {-Symbolic: use symbols to indicate something } \\
\text { - Abstract: take out a small bit of information and use it to } \\
\text { represent the whole thing } \\
\text { - Rational: draw conclusions based on reason and facts } \\
\text {-Digital: use numbers as in counting } \\
\text { - Controlled }\end{array}$ & $\begin{array}{l}\text {-Non-verbal: knowledge is achieved through images } \\
\text { - Synthesis: things are put together to form wholes } \\
\text { - Holistic: perceive the overall patterns and structures, can } \\
\text { process many kinds of information simultaneously, often } \\
\text { leads to divergent conclusions } \\
\text { - Divergent thinking } \\
\text { - Intuitive: make leaps of insight, often based on incomplete } \\
\text { patterns, feelings, hunches or visual images } \\
\text { - Subconscious or preconscious reasoning } \\
\text {-Analogic: understand metaphoric relationships and im- } \\
\text { agery, see likenesses between things } \\
\text { - Concrete: relate to things as they are at the present mo- } \\
\text { ment } \\
\text { - Non-rational: do not require a basis of reason or facts, will- } \\
\text { ing to suspend judgement } \\
\text {-Visio-spatial: see the relationship between things and how } \\
\text { the parts go together to form a whole } \\
\text {-Emotional: a product of the limbic system, but the right } \\
\text { hemisphere is more in touch with feelings }\end{array}$ \\
\hline
\end{tabular}


cations for education (Corballis 1980:286; Zdenek 1985:10).

The research that has been done on brain functioning and specialisation, attributes the left cerebral hemisphere with linear, verbal and analytic thinking processes, and the right hemisphere with non-verbal, synthesising and holistic processes. This clarifies why certain individuals tend to approach problems logically, analytically and factually (left brain mode); whereas others tend to approach problems intuitively using images, concepts and patterns (right brain mode).

The list of thinking processes of the left and right hemispheres of the brain illustrates the results of various research studies.

The myth that the right hemisphere is the one and only responsible for creativity, has been found to be untrue by recent research studies. The contemporary view on the nature of creativity is summarised in the following quotation by Williams (1983:4): ... the differences between the hemispheres should not obscure the fact that it is their complementary functioning that gives the mind its power and flexibility.

Creative work requires the combined abilities of intuitive awareness and logical thinking - a scientist needs his logical left hemisphere for analytical reasoning but it is his intuitive right hemisphere which provides that leap of insight that solves a complex problem. This concept is confirmed by Rubenzer in Gowan, Khatena and Torrance (1981:280) in the following quote: the most productive and creative intellectual functioning is theorised to occur when there is cooperation between hemispheres.

\section{From the eplit brain theory to the four quadrant model (Whole Brain Creativity Model)}

The Whole Brain Creativity Model explains how the brain functions while engaged in the creative process. It was developed by Herrmann (1989), and is based on the triune and left brain/right brain theories. The triune brain theory divides the brain into a Neomammalian (neocortex), Paleomammalian (limbic system) and reptilian brain. Whereas the left brain/right brain theory splits the brain into two cerebral hemispheres, Herrmann's whole brain creativity model divides the brain into four quadrants. The four quadrant concept includes the left and right cerebral hemispheres and the left and right halves of the limbic sys-

tem.

The Whole Brain Creativity Model was developed from data gathered during Brain Update Workshops during which Herrmann shared the results of the split brain research of the 1970 s with others. He distributed questionnaires containing questions on educational background, job focus, preferred academic subjects and hobbies, and choices between adjectives describing different functions of the specialised brain in which subjects had to select those pertaining to themselves. The instrument initially showed a linear profile which reflected the basic dichotomy between left brain related modes of mental processing and right brain related modes. As more people completed the questionnaire, the data base grew to show four distinct clusters (Herrmann 1989:50-53).

It took Herrmann some time to comprehend this phenomenon of the four clusters. He finally merged the triune brain theory and the left brain/right brain theory as the link he was looking for, appeared to be the limbic system. The two upper quadrants represent the left and right cerebral hemispheres and the two lower quadrants the left and right halves of the limbic system.

Although Herrmann originally thought of the whole brain model as a physiological map, he moved away from this interpretation to present the model as a metaphor. He stopped using the terms cerebral hemispheres and limbic system to soften the relationship between the physiology of the brain and the metaphoric model, and renamed the four quadrants, A, B, C and D (Herrmann 1989:63-65). Figure 1 illustrates the thinking processes attributed to each of the four quadrants in the Whole Brain Model.

The metaphoric model is regarded as more appropriate since determining precisely which part of the brain was doing what, has become more difficult and less important. Researchers have discovered that brain laterisation is not clear cut, but much more subtle, complex and versatile than they thought.

The metaphoric model has been proved a reliable replica of human brain specialisation when considering the results of the implementation of the Herrmann Brain Dominance Instrument. By 1989 more than 500000 people had completed the questionnaire and the study of the profiles indicates the distribution of brain dominance as follows:

Single dominant

Double dominant

Triple dominant
Quadruple dominant $=$

(Herrmann 1989:85)

According to Herrmann the HBDI measures preference for a mental activity but this does not necessarily means competence in performing it. Competence comes through training and experience, but world class competence can only be achieved in an area of preference. This is a very important statement as creativity is no superficial, aha-experience - it requires a lot of hard work, a thorough knowledge of a specific field, dedication and motivation and the use of all four quadrants of the brain.

Herrmann views people who are creative as having a primary preference for the D-quadrant, but says that they are supported by strong secondary preferences in other quadrants which enable them to function situationally in order to complete a creative task. Supporting capabilities, when strengthened, often enhance the original preference (Herrmann 1989:197). This concept is affirmed by Wenger who states that in order to improve any area of the brain, an individual should first work in the language of that part of the brain, and then combine the behaviour with the language of another part of the brain (Parnes 1992:254).

The premise that creativeness is a product of whole brain functioning has been expressed by many authors and researchers. Rubenzer quotes several, including Chiselin (1952), Gilchrist (1970), Kraft (1976) and Norman (1977), as having suggested that creative geniuses are most adroit at utilising both the left and the right hemispheric processing modes (Gowan, Khatena \& Torrance 1981:280). Herrmann expresses his view on this matter as follows: What becomes clear when one studies the lives and writings of scientific and artistic geniuses is that what made many of them extraordinary was their use and trust of modes that are non-dominant in their particular fields (Herrmann (1989:196).

The distinction between artistic and scientific creativity is made on the basis of the difference in primary processing modes. The artistic creative process is regarded as stronger right mode ( $\mathrm{C}$ - and D-quadrant) oriented, relying on nonverbal, visual, imaginative and spatial abilities, whereas scientific creativity relies on the left mode (A-and B-quadrant) processes which include logic, analytical, verbal and mathematical skills (see figure 1).

The relation between the four quadrant model and creativity can be illustrated by the examples of creative geniuses such as Da Vinci, Eistein and Kekulé. 


\section{Cerebral mode thinking processes}

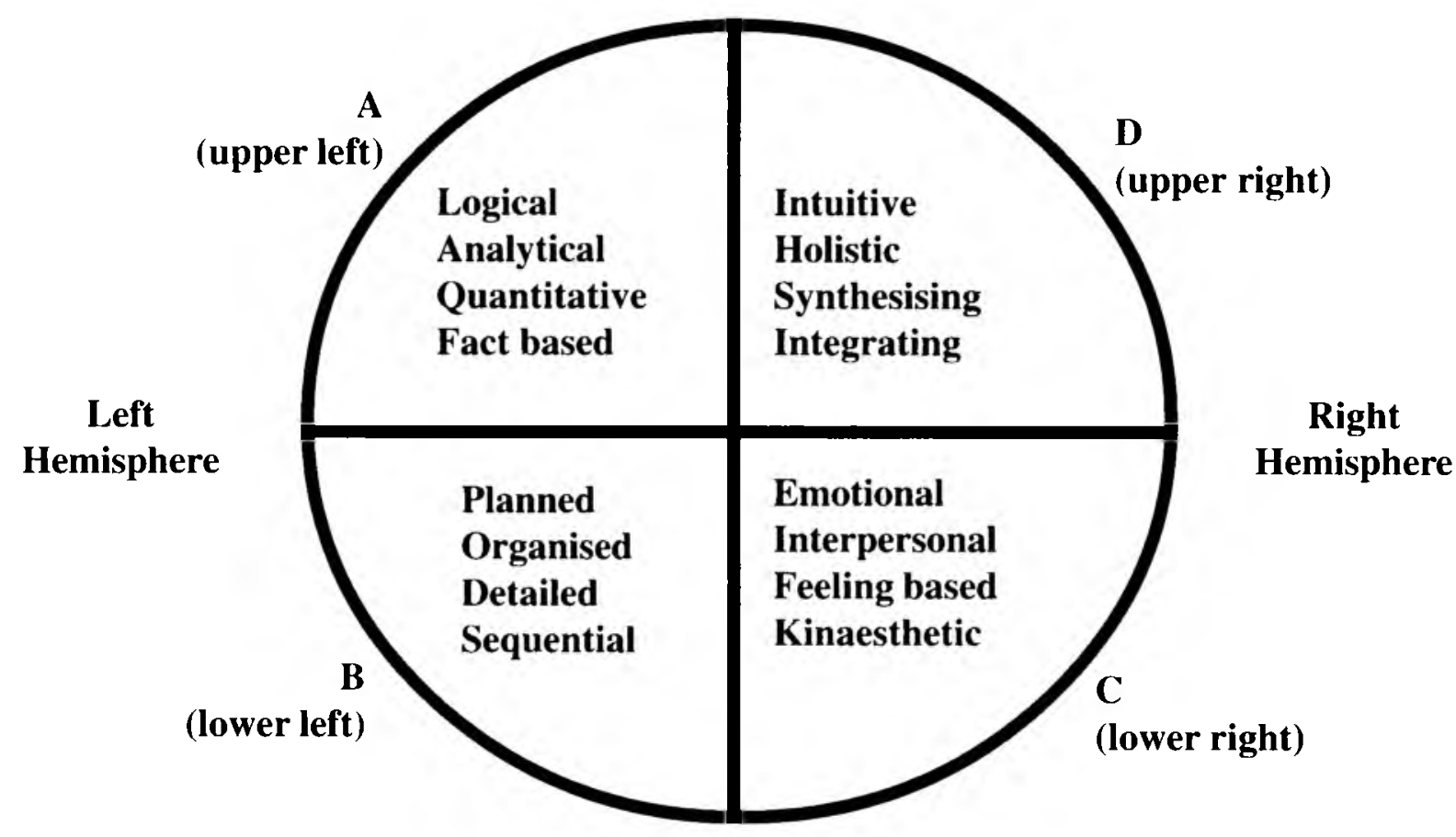

Cerebral mode thinking processes

(Adopted and adjusted from Herrmann 1989:411)

Leonardo da Vinci has been regarded as a multiple dominant scientific and artistic giant, as a result of his art works and scientific designs. Albert Einstein and August Kekule are perceived to have been double dominant (in the A- and Dquadrants) with the ability to move back and forth between these two specialised modes through iteration. This enabled them to bring two different mental processes into a synergistic whole. Einstein conceived his theory of relativity after he had a dream of himself riding on a light beam. He regarded his gift for fantasy as much more important than his gift for logic and analysis (Herrmann 1989:196197). Kekulé, a Dutch Chemist, discovered the molecular structure of benzene, the benzene-ring, through a dream after struggling with this problem over a very long period. He dreamed of atoms gambolling, twining and twisting in snake-like motion until one snake seized hold of its own tail and whirled mockingly - this lead to a sudden insight - the benzene-ring (Gowan, Khatena \& Torrance 1981:250).
Apart from Herrmann's metaphor, the interactive effects of the left and right hemispheres' processes have been emphasised by other recent cognitiveoriented metaphors for the creative process. Parnes (1977) regards the integration of the special abilities of both the left and right hemispheres as essential for creativity. Torrance (1978) supports the concept as manifested in his words:

In creative thinking, it is especially important to understand the specialised functions of the right and left hemispheres, since almost by definition both kinds of functioning are required (Elliott 1986:204).

\section{the whole brain teaching and learning model}

In addition to the whole brain creativity model, Herrmann developed a whole brain teaching and learning model. The learning process is divided into the four brain quadrants and summarised into two categories; structured and unstructured. The structured modes (A- and B- quadrants) focus on logical, rational, analytic and quantitative activities as well as the planned, organised, sequential and procedural elements of the learning process. The structured modalities are in sharp contrast with the unstruc tured modes (C- and D-quadrants) which focus on non-verbal, visual, conceptual and simultaneous processes involving emotional, interpersonal and expressive activities (Herrmann 1989:220-221) (figure 2).

The whole brain teaching and learning model can serve as a guide for nurse educators who wish to stimulate and facilitate whole brain learning and creativity in their students.

\section{Whole brain learning and design considerations}

According to Herrmann A-quadrant dominated individuals learn by acquiring and quantifying facts, applying analysis and logic, thinking through ideas building cases and formulating theories. 
They respond to formal lectures, case studies, programmed learning and textbooks with the focus being on the verbal, rational and abstract processes of the left hemisphere. Teaching strategies such as seminars, individual projects and reading assignments can be added to Herrmann's list to assist A-quadrant dominated learners (Herrmann 1989:419).

The B-quadrant dominated individuals learn by organising, structuring and sequencing content, evaluating and testing theories, acquiring skills through practice and implementing content (Herrmann 1989:419). They respond, like the A-quadrant individuals, to formal lectures, programmed learning, case discussions and textbooks but thorough planning and sequential order is added and emphasised. There tend to be a stronger focus on organisation and practical application in the B-quadrant and learning could be assisted by providing opportunities for demonstrations, practice sessions in the simulation laboratory, clinical learning experiences and group discussions (Potgieter 1996:79).

The A- and B-quadrants of the left hemisphere have some aspects in common. There is a need for a structured teaching-learning environment wherein the learners are disciplined, rational and verbally oriented concerned with the know how of information. The differences between A- and B-quadrants result from the differences between the left cerebral hemisphere (perceived as intellectual and fact based and the left half of the limbic system (kinaesthetically orientated and controlled). This explains the phenomenon that A-quadrant dominant individuals are achievement driven whereas B-quadrant dominant individuals are task driven.

In contrast to the left hemispheric thinking processes are the right hemispheric thinking processes which are divided into the D- and C-quadrant. D-quadrant dominated individuals learn by taking initiative, relying on intuition and self-discovery, exploring hidden possibilities, constructing concepts and synthesising content (Herrmann 1989:419). They respond to visual displays, experiential opportunities, aesthetic qualities, and future oriented case discussions. They tend to be spontaneous, playful, individualistic and enjoy being involved in the learning process. Compared to the left hemispheric functions the preference for non-verbal information and analogy, holistic perception, synthesising abilities and intuitiveness, are evident in D-quadrant functioning. Teaching strategies which could assist learning include individual patient case histories, guided fan- tasy, metaphorical thinking, simulation, role play and challenging clinical assignments such as developing health education brochures for individual patients.

The C-quadrant dominated individuals learn by feeling, moving and emotional involvement, integrating experiences with the self and harmonising with the content, listening and sharing ideas. They tend to respond to sensory movement and music, experiential learning, people oriented case discussions and group interaction. It can be deducted that because of the emphasis on the affective aspects in the C-quadrant, learning can be assisted by teaching strategies including group discussion, values clarification, role play, simulation games, clinical post conferences and field trips (Potgieter 1996:81).

Considering the whole brain teaching and learning model, it is obvious that the right hemispheric oriented individuals prefer experiential learning opportunities which allow for an unstructured teaching-learning environment providing opportunities for spontaneous and explorative learning. These individuals are good at non-verbal learning and are concerned with the know why of information. The differences between the D- and Cquadrants result from the specialisation of the right cerebral hemisphere which is more intellectually oriented and openminded, in contrast with the right half of the limbic system, which is kinaesthetically oriented with a strong emphasis on feelings and emotions. This clarifies why the D-quadrant dominant individuals are independence driven whereas the $C$ quadrant dominant individuals are feelings-driven.

\section{implications for nursing education}

The whole brain teaching and learning model can assist nurse educators to implement a holistic approach towards teaching. By utilising a variety of teaching strategies, the nurse educator can stimulate all four quadrants of the student nurse's brain. For example, a student who is double dominant in the $A$ and B-quadrants will prefer to learn through formal lectures, case studies, learning packages, programmed learning, reading assignments, etc (see figure 3). However, these students need stimulation of the $D$ and $C$-quadrant thinking processes in order to develop whole brain learning and creativity. They should therefore also be exposed to teaching strategies including simulation, clinical assignments, patient case histories, role play, values clarification, field trips, etc (see figure 3 ). Figure 3 serve as an example, there are however many other teaching strategies which could be added.

\section{implications for nursing practice: whole brain creativity and the expert nurse practitioner}

The human science of nursing is founded upon an epistemology that includes metaphysics, aesthetics, humanities, art and empirics. It respects intuition, compels logic and reason, exacts discipline, necessitates critical thinking, requires creativity, views the individual holistically and has caring as its ethical imperative (Bevis \& Watson 19890:220, 221; Chaska 1990:101, 227; Watson 1985:29). These assets refer to a combination of left and right brain processes. Intuition is a D-quadrant process; logic, reason and critical thinking are A-quadrant processes; exacting a discipline requires both $\mathrm{A}$ - and B-quadrant processes; and caring originates in the $C$ quadrant.

Aydelotte in Benner (1984: $\mathrm{V}$ ) refers to the mystery of expert nursing practice and calls for respect for this mystery rather than to dispel or standardise practice by submitting it to rules and procedures. Schein (1972) refers to the important component of a professional programme as training for uncertainty. It implies a willingness to take responsibility for key-decisions that may be based only on partial information and the willingness to make decisions under conditions of high risk (Reilly \& Oermann 1992:7-8).

According to Benner (1983), nursing practice is always more complex (than to put theory learned in the classroom into practice) and presents many more realities than can be captured by theory alone (Reilly \& Oermann 1992:5).

Nurses are confronted daily by unique and complex patient- or setting-oriented problems which require the ability to use concepts and theories in order to find solutions. Not all problems lend themselves to resolution through application of theory and a technical approach. Analytical reasoning is useful in structured settings but nursing practice invariably involves highly complex interacting elements which require analytical and non-linear thinking processes. Recent studies question the merits of exclusive attention to a logical, analytical and linear process of reasoning in practice related problems (Miller \& Rew 1989:8485; Reilly \& Oermann 1992:221). Whereas these thinking skills relate to $A$ and B-quadrant processes, specific $\mathrm{C}$ and D-quadrant processes, which in- 
Figure 2 : Whole brain teaching and learning model

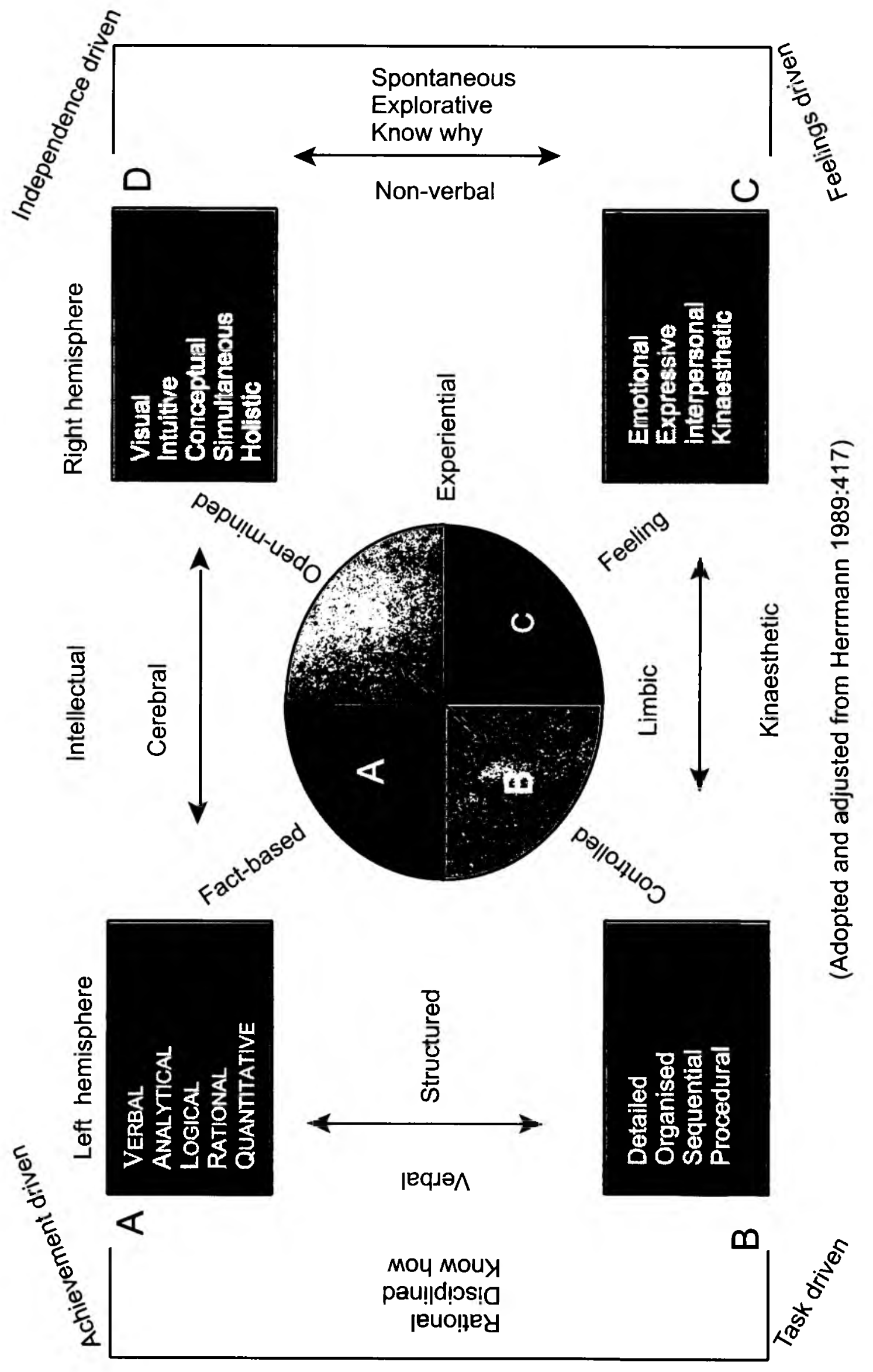




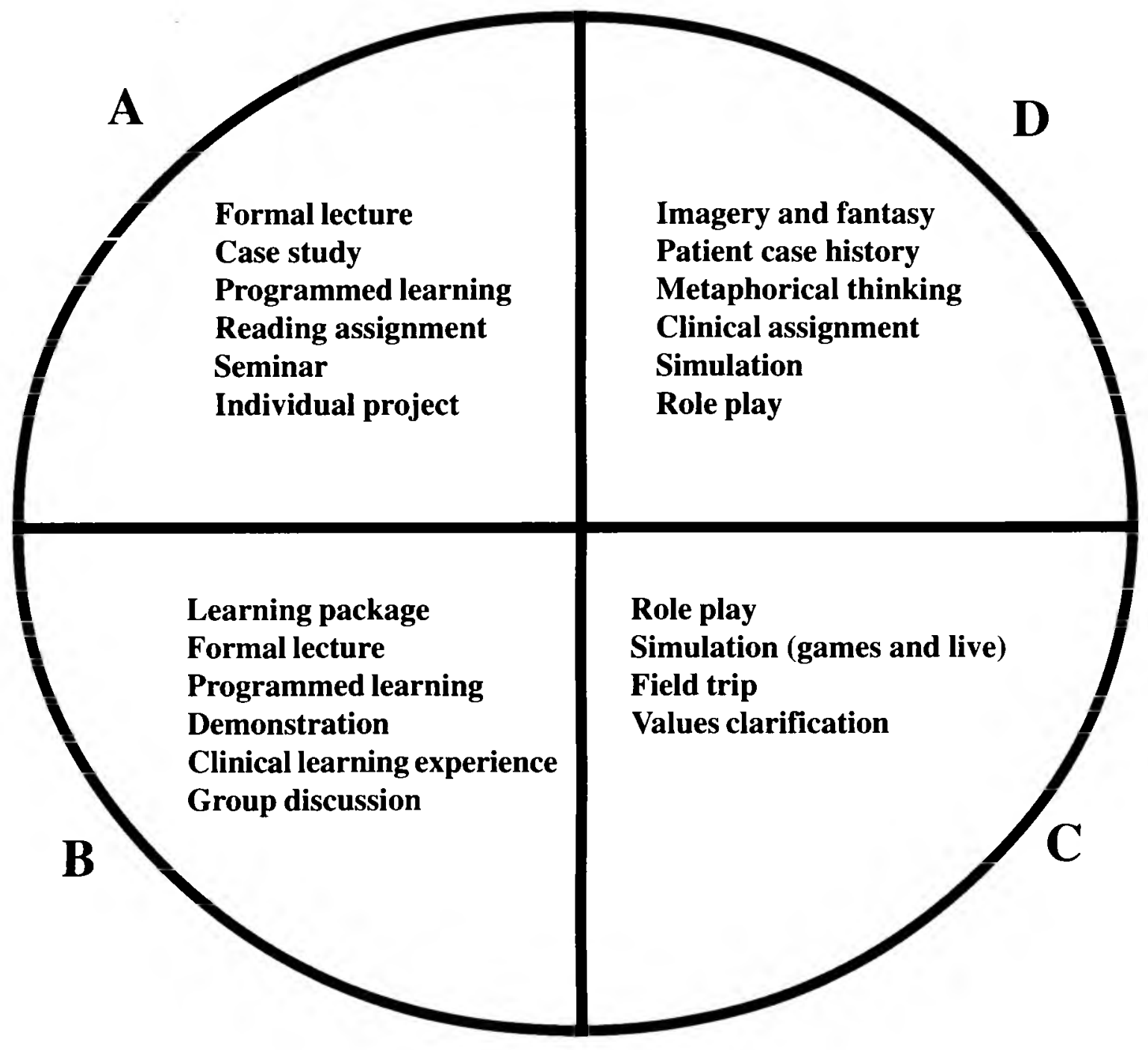

(Potgieter 1996:80)

clude intuition, a holistic perspective, synthesis and emotional aspects, are also essential to render client specific care.

The necessity for whole brain creativity in nursing practice is illustrated in the following quote by Isabel Steward in Donahue (1985:467): Technique, mind, soul and imagination are all essential in the foundation of a true artist. The nurse as a true artist is essential to the progression of nursing into something other than a highly skilled trade.

Benner affirms the role of intuition in solving clinical problems and making nursing judgements. According to Benner, experts dare not stop with vague hunches, but neither do they care to ignore those hunches that could lead to early identification of problems and the search for confirming evidence (Benner 1984:xix).
The expert nurse gets a gestalt on a situation and has an intuitive grasp of the situation. She zeroes in on the accurate region of the problem without consideration of unfruitful alternative diagnoses and solutions because of her background of experience. By using concrete situations as paradigms, evaluating alternatives on the basis of comparison of salient elements, and perceiving the situation as a whole, the expert nurse arrives at a holistic decision.

A study conducted by Davies to determine whether observation of clinical role models could lead to knowledge and discovery, revealed the following. Students reported that they recognised creativity and flexibility in nurse practitioners and related these attributes to the ability to provide individualised, contextspecific care. They labelled the more experienced nurses as calm, pleasant, spontaneous, helpful, flexible, very inter- ested, excellent, organised, well-informed, brilliant, capable and outgoing (Davies 1993:631, 635).

The expert nurse thus appears to utilise whole brain thinking as thinking processes from all four quadrants are apparent in these attributes. "Intuitive grasp" and "holistic perception" refer to the Dquadrant; "calm", "pleasant" and "spontaneous" refer tot he C-quadrant; "organised" and "using concrete situations as paradigms" refer to the B-quadrant; "evaluating alternatives", "well-informed" and "excellence" refer to Aquadrant processes.

When asked to cast their role models in the care provider role the students in Davies's study recognised the following abilities and skills. The abilities of the nurse practitioners to constantly adjust and adapt to changes in the profession 
to modify approaches to suit the context, and to deal with conflicting needs. Practical competence in divergent situations - where problems were contextually specific and not well-defined and which resulted in conflicting values - were also noted. Bevis and Clayton (1988), Smyth (1988) and Speedy (1989) regard context specificity as the hallmark of creativity and individualised nursing practice (Davies 1993:634).

\section{summary}

The Whole Brain Creativity Model provides a sound basis for understanding the concept "creativity" as illustrated in the works of scientific geniuses. It also offers hope to each individual who wishes to develop his/her own creativity. The principles of whole brain learning and teaching provide a strong argument for the development of creativity in student nurses with the ultimate aim of producing an innovative and effective nurse practitioner.

\section{bibliography}

Appleton, C. 1993. The art of nursing: the experience of patients and nurses Journal of Advanced Nursing, 18:892-899.

Benner, P. 1984. From novice to expert: excellence and power in clinical nursing practice. Menlo Park California: Addison-Wesley.

Bevis, E.O. \& Watson, J. 1989. Toward a caring curriculum: a new pedagogy for nursing. New York: National League for Nursing

Chaska, N.L. 1990. The nursing profession: turning points. St Louis: Mosby

Corballis, M.C. 1980. Laterality and myth. American Psychologist, 35(3):284-295.

Davies, E. 1993. Clinical role modelling: uncovering hidden knowledge. Journal of Advanced Nursing, 18:627-636.

Davis, G.A. 1986. Creativity is forever. Dubuque: Kendall Hunt.

Donahue, MP.. 1985. Nursing the finest art. St Louis:Mosby.

Elliot, P.C. 1986. Right (or left) brain cognition, wrong metaphors for creative behaviour: it is prefrontal lobe volition that makes the (human/humane) difference in the release of creative potential. The Journal of Creative Behaviour, 20(3):202-214

Gowan, J.C., Khatena, J. \& Torrance, E.P. 1981. Creativity: its educational implications. 2nd edition. Dubuque:Kendall Hunt.

Herrmann, Ned. 1989. The creative brain. Lake Lure: Ned Herrmann Group.

Holbert, C.M. \& Thomas, K.J. 1988. Toward whole brain education in nursing. Nurse Educator, 13(1):30-34.

Klein, R.D. 1973. Evolving creative behaviour. Ed D Thesis, University of Massachusetts. Ann Arbor, Michigan: University Microfilms International.

Kolb, D.A. 1984. Experiential learning: experience as the source of learning and development. New Jersey: Prentice-Hall.

Miller, V.G. \& Rew, L. 1989. Analysis and intuition: the need for both in nursing education. Journal of Nursing Education, 28(2):84-86

Oschse, R. 1988. A theoretical study of the determinants of creativity. (PhD thesis. Unisa). Pretoria.

Parnes, S.J. (Ed). 1992. Source book for creative problem-solving. Buffalo, NY: Creative Education Foundation Press.

Potgieter, E. 1996. Innovative teaching strategies within a nursing education model. (D Litt et Phil thesis: Unisa). Pretoria.

Prinsloo, N.M. 1973. Die invloed van spesifieke metodes op die ontwikkeling van kreatiewe denke - 'n empiriese studie. (D Ed proefskrif : Unisa). Pretoria.

Reilly, D.E. \& Oermann, M.H. 1992. Clinical teaching in nursing education. New York: NLN.

Rothenberg, A. \& Hausman, C.R. (Eds.) 1976. The creativity question. Durham NC: Duke University Press.

Saylor, C.R. 1990. Reflection and professional education: art, science and competency. Nurse Educator, 15(2):8-11.

Sisk, D. 1987. Creative teaching of the gifted. New York: McGraw-Hill.

Watson, J. 1985. Nursing: human science and human care. New York: NLN.

Williams, LV. 1983. Teaching for the two-sided mind. Englewood Cliffs: Prentice Hall.

Zdenek, M. 1985. The right brain experience. New York: McGraw Hill. 